\title{
Staff Perceptions and Barriers to ED Based HIV Testing in an Urban Academic ED
}

\author{
Fredric M. Hustey, Michael P. Phelan*, Sharon O’keefe and Tracy M. Barbour \\ Emergency Services Institute, Cleveland Clinic, Cleveland, OH, USA
}

\section{Objective}

To evaluate ED staff attitudes and potential barriers towards ED based POC HIV testing in an urban academic ED prior to implementing an ED based POC HIV test.

\section{Introduction}

In 2003, the Centers for Disease Control and Prevention (CDC) in Atlanta, Georgia estimated that approximately 1 million people in the United States were living with HIV/AIDS, and that approximately $25 \%$ these were undiagnosed and unaware of their HIV infection. For many such patients the emergency department may be the only part of the health care system that is utilized. In 2006, the CDC revised their recommendations for HIV testing in a variety of care settings including the emergency department (ED). Early identification and treatment improves survival for patients with HIV. Earlier testing programs including those provided in the ED will lead earlier detection and further reduction in the transmission of HIV in the United States. $(1,2,3)$ The analysis was focused on ED providers' knowledge and attitudes towards routine HIV testing, perceived barriers to HIV testing

\section{Methods}

Methods: Prospective survey of staff (board-certified emergency physicians, nurses, and physician assistants) in an urban tertiary care ED with affiliated residency program using a previously published and validated assessment tool for these purposes. The survey was administered by research staff as hard copy and hand completed by participants. It consisted of a series of questions regarding perceptions and attitudes towards ED based HIV testing with response options ranging from strongly disagree to strongly agree on a 5 point likert scale, followed by the question "The following are barriers that would prevent me from providing rapid HIV testing, (mark ALL that apply)" consisting of 11 choices. Results were entered into an electronic database for analysis by a trained analyst. Proportions with $95 \%$ confidence intervals are reported.

\section{Results}

There were 69 total respondents $(21 / 23$ (91\%) staff physicians, $8 / 10(80 \%)$ physician assistants, $40 / 55(73 \%)$ full time emergency nurses). Top barriers identified were perceptions of inadequate time/ no desire to provide the required counseling (37/69 (54\%) concern of increase in volume of ED patients presenting for HIV testing $(36 / 69$ (52\%) and confidentiality/privacy concerns (26/69 (38\%). Only 41\% $(28 / 69)$ of participants agreed that they were comfortable discussing an HIV positive test result with a patient (PAs 4/8, 50\%; 95\%CI 2278 , physicians $13 / 21,62 \%$; $95 \%$ CI $41-79$, nurses $11 / 40,28 \%$; $95 \% \mathrm{CI}$, $16-43)$. Only $30 / 69$ (43\%) of the respondents disagreed or strongly disagreed that offering rapid HIV testing would take too much time and would interfere with job duties $11 / 21(52 \%, 95 \%$ CI $32-72 \%)$ physicians, $2 / 8(25 \%, 95 \% \mathrm{CI}, 6-60)$, physician assistants, $17 / 40(43 \%$, $95 \%$ CI, 29-58\%) nurses.

\section{Conclusions}

In spite of recent $\mathrm{CDC}$ recommendations for HIV testing in high risk ED patients, there are still significant barriers to acceptance among ED health care providers related to health care provider perceptions and attitudes. Educating ED care providers regarding current laws related to HIV testing as well as increasing receptiveness to discussing HIV + results and may help to address some of these issues.

\section{Keywords}

HIV; emergency department; testing; public health

\section{References}

1. Glynn M, Rhodes P. Estimated HIV prevalence in the United States at the end of 2003. National HIV Prevention Conference; June 2005; Atlanta. Abstract T1-B1101. Available at: http://www.aegis.com/conferences/NHIVPC/2005/T1-B1101.html. Accessed February 11, 2008.

2. CDC MMWR, August 8, 2008 / 57(31);845-849 http://www.cdc.gov/ $\mathrm{mmwr} / \mathrm{preview} / \mathrm{mmwrhtml} / \mathrm{mm} 5731 \mathrm{a} 1 \mathrm{htm}$, accessed June 25, 2013

3. Branson BM. Revised recommendations for HIV testing in healthcare settings. Available at: http://www.cdc.gov/hiv/topics/testing/ resources/slidesets/pdf/

testing_healthcare.pdf. Accessed February 12, 2008.

*Michael P. Phelan

E-mail: phelanm@ccf.org 